\title{
La figura del idiota en la filosofía de Gilles Deleuze, considerada a partir de algunas de sus fuentes (Cusa, Descartes, Dostoievski)
}

\author{
The Figure of the Idiot in the Philosophy of Gilles Deleuze \\ considered from some of its sources (Cusa, Descartes, Dostoevsky)
}

AXEL CHERNIAVSKY*

\begin{abstract}
Resumen: En la vida cotidiana y el lenguaje corriente, muchas veces la idiotez remite a una falta de inteligencia o a un defecto del pensamiento. Se trata de una concepción que alcanzó gran precisión en la psiquiatría clásica y que no se halla totalmente ausente de la filosofía contemporánea. Sin embargo, a juicio de Deleuze y Guattari, el idiota constituye el personaje filosófico por excelencia. ¿En qué medida este personaje supone o permite construir una concepción alternativa de la idiotez? En realidad, existen tres tipos de idiotas en la obra de Deleuze: uno que se identifica con el tonto, otro que se identifica con el loco y un tercero que ríe de la creencia en este mundo. Intentaremos ofrecer una respuesta al interrogante anterior analizando cada uno de estos tres personajes.

Palabras clave: idiotez, tontería, locura, pensamiento, conocimiento, creación.
\end{abstract}

\begin{abstract}
In everyday life and common language, idiocy often refers to a lack of intelligence or a defect in thinking. This conception achieved great precision in classical psychiatry and it is not totally absent from contemporary philosophy. However, according to Deleuze and Guattari, the idiot constitutes the philosophical persona par excellence. To what extent does this persona entail or allow constructing an alternative conception of idiocy? Actually, there are three kinds of idiots in Deleuze's work: one that identifies itself with the fool, another that identifies itself with the madman and a third that laughs at the belief in this world. We will try to offer an answer to the aforementioned question by analyzing each of these three characters.
\end{abstract}

Keywords: idiocy, foolishness, madness, thought, knowledge, creation.

Recibido: 02/08/2018. Aceptado: 13/11/2018.

* Investigador en el Consejo Nacional de Investigaciones Científicas y Técnicas (Argentina), en el Centro de Investigaciones Filosóficas (Argentina) y Profesor en las cátedras de Filosofía Contemporánea y de Metafísica en la Facultad de Filosofía de la Universidad de Buenos Aires. Recientemente publicó Spinoza (Buenos Aires, Galerna, 2017) y "Del idiota de la comunidad a la comunidad de los idiotas" (en Cragnolini, M., Comunidades (de los) vivientes, Buenos Aires, La cebra, 2018). El presente artículo se inscribe dentro de una investigación más amplia, que interroga la figura cultural del idiota a partir de fuentes filosóficas, literarias y psiquiátricas. 


\section{Introducción}

Cuando la idiotez se contaba entre los cuadros clínicos de la psiquiatría clásica, era definida como una deficiencia mental. Así, en el momento en que la disciplina daba sus primeros pasos, Philippe Pinel describía la idiotez como la "abolición más o menos absoluta, ya sea de las funciones del entendimiento, ya sea de las afecciones del corazón"1 (Pinel, 1800, 166), y más de un siglo después, Emil Kraepelin, en la octava edición de su tratado, la presentaría como "la postración completa de todos los impulsos espirituales" [das völlige Darniederliegen aller geistigen Regungen] (Kraepelin, 1915, 2173). La idiotez era una enfermedad, a veces incluso una falta moral, y consistía en una privación parcial o total de las facultades mentales.

Hoy en día, el cuadro ha sido sustituido por las descripciones de los trastornos del neurodesarrollo ${ }^{2}$, pero ciertas definiciones de fenómenos afines parecen conservar las características de las descripciones del pasado. Alain Roger, por ejemplo, en su Breviario de la tontería, define a ésta, a la estupidez y a la ingenuidad, como un abuso de los principios lógicos, en particular del principio de identidad, del principio de contradicción y del principio del tercero excluido, respectivamente (Roger, 2008, 40). Y si Clément Rosset, en su Tratado de la idiocia, afirma que la imbecilidad no se opone a la inteligencia, dado que el imbécil en general consigue lo que se propone, eso que se propone, prosigue Rosset, suele parecerse al acto de cortar la rama en la que está sentado (Rosset, 2004, 178). Pareciera entonces que estos fenómenos también son pensados como dificultades o limitaciones que conciernen a la esfera mental, y que la concepción de la idiotez de la psiquiatría clásica conserva cierta vigencia, no sólo en la vida cotidiana y el lenguaje corriente.

¿En qué medida los desarrollos de Gilles Deleuze, sobre todo en el último libro escrito en colaboración con Félix Guattari, ¿Qué es la filosofía?, permiten construir una concepción alternativa de la idiotez? En cierto sentido, cabe esperarlo, no sólo porque en ¿Qué es la filosofía? Deleuze y Guattari oponen la filosofía al sentido común y distinguen la filosofía de la ciencia (Deleuze y Guattari, 1991, 76-77), sino porque allí el idiota parece constituir el personaje filosófico por excelencia. En efecto, el tercer capítulo del libro, dedicado a los personajes conceptuales, comienza con el ejemplo del idiota. ¿Por qué? Porque, en principio, el idiota ejercería la actividad propiamente filosófica que, a juicio de Deleuze y Guattari, consiste en crear conceptos (Deleuze y Guattari, 1991, 10). La idiotez, lejos de oponerse al pensamiento, se identificaría así con una de sus formas, a saber, la creación conceptual.

Sin embargo, el problema es más complejo de lo que parece, ante todo, porque en ¿Qué es la filosofía? no hay un solo idiota, sino dos tipos que Deleuze y Guattari distinguen como el "antiguo" y el "nuevo". Del primero, afirman que "quiere evidencias a las que llegaría por él mismo"; del segundo, que quiere "hacer de lo absurdo la más alta potencia del pensamiento" (Deleuze y Guattari, 1991, 61). ¿Quiénes son estos personajes? ¿Qué concepción de la idiotez presuponen y, en particular, qué relación guardaría ella con el pensamiento? Analizando ambas figuras, intentaremos mostrar cómo, de acuerdo con la

1 Salvo indicación contraria en la bibliografía final, las traducciones son nuestras.

2 A saber, la discapacidad intelectual, en la quinta versión del Manual diagnóstico y estadístico de los trastornos mentales (APA, 2013, 33-41), y el retraso mental, en la décima versión de la Clasificación internacional de las enfermedades (OMS, 1995, 356-357), correspondientes a las códigos F70-F79 en ambas clasificaciones. 
primera, la idiotez sigue siendo considerada como un obstáculo para el pensamiento y cómo, de acuerdo con la segunda, si bien la idiotez parece formar parte del pensamiento, su definición conserva los presupuestos de la figura anterior. En un tercer momento, a partir de la fugaz aparición de lo que creemos que constituye un tercer tipo de idiota en la filosofía de Deleuze, nos preguntaremos si no es posible construir, a partir de él, una definición verdaderamente alternativa de la idiotez.

\section{El viejo idiota, o el tonto}

El tercer capítulo de ¿Qué es la filosofía? está dedicado a lo que Deleuze y Guattari llaman los "personajes conceptuales" y comienza por una descripción del idiota. Esto sugiere que no se trata de un personaje cualquiera, sino de un personaje privilegiado. ¿Quién es este idiota y por qué tendría un rol especial en la definición de la filosofía? ¿Qué concepción de la idiotez supone y, en particular, qué relación permite establecer entre la idiotez y el pensamiento?

A primera vista, el idiota de ¿Qué es la filosofía? corresponde al personaje de los célebres diálogos de Nicolás de Cusa y de Descartes, la trilogía Idiota y La búsqueda de la verdad mediante la luz natural. ¿Por qué es un idiota? Deleuze y Guattari no mencionan lo que para nosotros tal vez sea lo más evidente: suerte de ignorante, el idiota está privado de un cierto saber. En efecto, cuando en el De mente de Nicolás de Cusa, el orador y el filósofo encuentran al idiota, éste se confiesa "rudo e ignorante" (Cusa, 2005, 41 [55])33, y Descartes, al presentar a Eudoxo, escribe que sólo supone "un hombre de mediocre espíritu" (Descartes, 1953a, 881). Así, la caracterización del personaje recoge ante todo la acepción latina del término idiota, que significa la ausencia de instrucción o incultura. En su forma griega, sin embargo, el término idiótes remitía al particular, al hombre que no se inmiscuía en las cuestiones de la polis. Tal vez esta significación resulte algo ajena para nosotros, pero es sobre ella que Deleuze y Guattari van a insistir: "El idiota es el pensador privado por oposición al personaje público (el escolástico)" (Deleuze y Guattari, 1991, 60). En efecto, si bien el idiota cusano se confiesa rudo e ignorante, agrega que a nada teme responder, ya que "los filósofos letrados y que tienen fama de poseer ciencia, justamente porque temen caer, deliberan con mayor gravedad" (Cusa, 2005, 42-43 [55]); y si bien Eudoxo es un hombre de mediocre espíritu, no hay que olvidar que su juicio "no fue pervertido por ninguna falsa creencia, y que posee toda la razón según la pureza de su naturaleza" (Descartes, 1953a, 881). El idiota, entonces, no es simplemente quien no sabe nada o sabe poco, sino quien hace la crítica de un cierto saber a partir de otro. De esta manera, una acepción no excluye la otra y reuniendo a ambas podríamos decir que, privado del saber establecido u oficial, el idiota es capaz de inventar un saber privado.

He aquí por qué el idiota no es un simple ejemplo de personaje filosófico, sino el personaje filosófico por excelencia. He aquí por qué el capítulo dedicado a los personajes conceptuales empieza por él: "el profesor no deja de remitir a conceptos enseñados (...), mientras que el pensador privado forma un concepto...” (Deleuze y Guattari, 1991, 60). El idiota es quien

3 Entre corchetes, consignamos el número de página del De mente en la edición de las obras completas de Nicolás de Cusa por L. Baur y R. Steiger. Se consultarán los datos bibliográficos en la lista de referencias. 
forma, inventa, crea conceptos, realizando así lo que para Deleuze y Guattari constituye el objetivo de la actividad filosófica. Por eso el idiota es el personaje conceptual por excelencia. Sin embargo, Deleuze y Guattari, van a agregar que este idiota "quiere evidencias a las que llegaría por él mismo" y que, mientras tanto, "pondría en duda todas las verdades de la Naturaleza", "dudaría de todo, incluso de $3+2=5$ " (Deleuze y Guattari, 1991, 61). ¿Qué significan estas afirmaciones? ¿A qué se refieren Deleuze y Guattari? Estas afirmaciones indican en qué o cómo piensa el idiota y, por lo tanto, describen la forma en la que la idiotez se relaciona con el pensamiento. Tal vez lo hagan de un modo algo veloz u obscuro. A nuestro juicio, esto se debe a que, implícitamente, retoman las reflexiones sobre el pensamiento que Deleuze expuso más de dos décadas antes en Diferencia y repetición. Por eso creemos que es inevitable recurrir a ellas y, al menos, recapitular de manera sucinta las que permitan completar la caracterización del idiota y comprender la concepción de la idiotez involucrada.

Uno de los objetivos de Diferencia y repetición consiste en forjar un verdadero concepto de la diferencia, es decir, el concepto de una diferencia que no se subordine o subsuma a una identidad o semejanza mayor, como es el caso, por ejemplo, de la diferencia entre dos especies en relación a la identidad del género del que forman parte. Para ello, Deleuze, por un lado, debe revisar las concepciones filosóficas de la diferencia. Por otro, debe revisar también las herramientas y los medios con los que intentamos dar cuenta de ella porque es posible que, en la medida que tengan la función de subsumir un material heterogéneo en una forma idéntica, se revelen como herramientas y medios problemáticos. Estas herramientas y estos medios corresponden a las facultades y sus productos y, por este motivo, encontramos en el tercer capítulo de Diferencia y repetición una reflexión sobre el pensamiento y lo que significa pensar. La reflexión combina dos procedimientos: por una parte, Deleuze realiza la crítica de una "imagen dogmática del pensamiento", reconstruida a partir de ciertas fuentes filosóficas clásicas; por otra, Deleuze construye lo que, recurriendo a otros textos (Nietzsche y la filosofía, por ejemplo), podríamos llamar una "nueva imagen del pensamiento". Ambas son presentadas a través de ocho tesis, pero nosotros nos detendremos sólo en aquellas que nos permitan avanzar en la interrogación de la idiotez.

En primer lugar, de acuerdo con la reconstrucción deleuziana de la imagen dogmática del pensamiento, el fin, el objetivo del pensamiento consistiría en saber, es decir, en una síntesis ideal de todos los conocimientos (Deleuze, 1968, 214). Luego, en el camino del saber, lo peor que podría sucederle al pensamiento, lo "negativo" del pensamiento en términos de Deleuze, correspondería al error, es decir, a la confusión entre lo verdadero y lo falso (Deleuze, 1968, 193). Sin embargo, es el tercer postulado, el que concierne al modelo del pensamiento, el que en el fondo explica en qué consistiría pensar según esta imagen: si el fin del pensamiento es el saber y el riesgo, el error, es porque pensar consiste en conocer y porque el reconocimiento constituye el modelo del conocimiento (Deleuze, 1968, 174). De acuerdo con la imagen dogmática del pensamiento, entonces, pensar sería conocer, conocer sería reconocer o, en otras palabras, decir "hola Teeteto" cuando efectivamente encontramos a Teeteto, ironiza Deleuze para sugerir el modo en que esta imagen banaliza el pensar (Deleuze, 1968, 176).

Comprendemos entonces por qué el pensamiento así concebido sería incapaz de obtener un verdadero concepto de la diferencia. Mientras el objetivo del pensar sea reconocer, identificar lo desconocido con lo conocido, asimilar lo extraño a lo familiar, la diferencia 
no podrá ser percibida. De aquí que Deleuze experimente la necesidad de construir lo que llama una "nueva imagen del pensamiento". Fundamentalmente, en esta nueva imagen del pensamiento, el modelo del pensar no consistirá en el reconocimiento, sino en la creación (Deleuze, 1968, 192). De acuerdo con la nueva imagen, pensar será crear - lo que resulta coherente con el objetivo de Diferencia y repetición. Luego, desde el momento en que el pensar se concibe como una creación, el fin y objetivo del pensamiento no consistirán en saber, sino en aprender, es decir, en la necesidad de revisar nuestras facultades y sus productos ante la sorpresiva experiencia de una novedad (Deleuze, 1968, 213-214). Y finalmente, si el objetivo del pensar no consiste en conocer y el fin no consiste en saber, se deduce también que ahora el riesgo no corresponderá al error definido como la confusión entre lo verdadero y lo falso, sino a algo más grave, a juicio de Deleuze, que recibirá el nombre de "tontería" [bêtise] (Deleuze, 1968, 194). Obligados a dejar de lado las diversas definiciones técnicas que aparecen en Diferencia y repetición ${ }^{4}$, reduciremos esta tontería a la incapacidad para pensar la diferencia, a la incapacidad para crear en el pensamiento.

¿Cómo interpretar ahora, a la luz de esta recapitulación, las afirmaciones de ¿Qué es la filosofía? que conciernen al idiota? Deleuze y Guattari nos decían que el idiota "quiere evidencias a las que llegaría por él mismo" y que, mientras tanto, "pondría en duda todas las verdades de la Naturaleza", "dudaría de todo, incluso de $3+2=5$ " (Deleuze y Guattari, 1991, 61). ¿A qué se refieren entonces? Decíamos que estas afirmaciones indicaban cómo o en qué piensa el idiota. Precisamente, indican que el objetivo del idiota es conocer. Por eso duda y desea evidencias. El objetivo del idiota es conocer, su ideal, saber, y el riesgo, equivocarse. Y bien podrá lograrlo, podrá evitar el error pero, de acuerdo con su caracterización, no podrá crear conceptos, es decir, pensar de verdad. Por eso, en los términos de Diferencia y repetición, estrictamente, es un tonto. Conoce, pero no piensa; podrá estar en lo cierto, pero no crear conceptos.

De esta manera, la idiotez parece quedar definida nuevamente como una negación del pensamiento. Identificada a la tontería, no se opone al pensamiento como conocimiento, pero sí al pensamiento como creación. Es cierto, el pensamiento fue redefinido. Deleuze ya no lo entiende como conocimiento sino como creación. Pero no por eso la idiotez deja de constituir su negación. No se opone como el error se opone al conocimiento, pero sí como la tontería a la creación. En este sentido, hasta aquí, hay que decir de la concepción de Deleuze y Guattari de la idiotez lo mismo que Heidegger decía del nihilismo incompleto: los valores pueden cambiar de forma y contenido, pero no parecen cambiar de lugar (Heidegger, 1977, 226). El pensamiento ha sido redefinido como creación y con él la idiotez como incapacidad para crear. Pero el pensamiento se sigue asimilando al bien, la idiotez, al mal, y entre ambos sigue habiendo una oposición. No hay dudas, la idiotez se distingue del error en tanto ya no consiste en una confusión entre lo verdadero y lo falso. Pero en tanto se identifica con la tontería, impide la creación y por eso constituye una nueva negación del pensamiento.

Ahora bien, ¿por qué entonces el idiota sería todavía el personaje paradigmático de la filosofía? ¿No implica esto una contradicción? ¿Cómo puede, al mismo tiempo, "formar conceptos" y "buscar evidencias", tal como se dijo? No creemos que simplemente haya que distinguir la filosofía de Deleuze y Guattari de las filosofías que ellos critican (en este caso,

4 Se consultarán las pp. 197, 207 y 245. 
las de Nicolás de Cusa y Descartes), como se distinguen lo verdadero de lo falso, o el éxito del fracaso. No creemos que el sentido de la concepción de la filosofía de Deleuze y Guattari implique que Descartes sea un tonto. Creemos que hay que distinguir el personaje del autor, por decirlo de alguna manera. El idiota, el tonto es el personaje, pero no el autor. Eudoxo, no Descartes. ¿Por qué? Porque por más que la figura de Eudoxo implique una concepción del pensar en la que el pensamiento equivale al conocimiento, esa imagen había que crearla, había que inventarla. Y esa imagen y los personajes que le corresponden son la invención de Descartes. La pregunta que entonces debe formularse ahora es qué clase de personaje filosófico es Descartes mismo para Deleuze y Guattari. No se trata ya del personaje creado por Descartes, que sólo permite dar cuenta del cuestionamiento del saber escolástico. Se trata ahora de un personaje que pueda dar cuenta de las creaciones conceptuales de Descartes y, claro está, de Deleuze y Guattari mismos. Se trata de un personaje cuyo fin sea crear y no sólo conocer. ¿Existe un personaje con estas características y que, como tal, pueda, por un lado, conservar el título de personaje filosófico por excelencia en el marco de la concepción de la filosofía de Deleuze y Guattari y, por otro - más importante -, ofrecer una concepción alternativa de la idiotez? Ese personaje existe, también es un idiota, y su contexto, según Deleuze y Guattari, es “todavía cristiano, pero ruso” (Deleuze y Guattari, 1991, 61).

\section{El nuevo idiota, o el loco}

"Si vamos a hacernos los idiotas, hagámoslo a la rusa" afirmaba Deleuze ya en Diferencia y repetición (Deleuze, 1968, 171). ¿A qué se refería? ¿Quién es este idiota ruso? ¿En qué medida podría ser un agente de creación conceptual y eventualmente representar una nueva concepción de la idiotez? Evidentemente, Deleuze se refiere al personaje de Dostoievski y, en 1991, particularmente a través de una lectura de Chestov que le permite mantener la oposición entre el profesor público y el pensador privado (Deleuze y Guattari, 1991, 61). Por eso el personaje sería todavía un idiota. ¿Pero por qué ruso específicamente? ¿Cuáles serían sus características propias? Tal vez sea particularmente significativo que, en su desmoronamiento final, en su regreso a la plena idiotez, el protagonista de la novela de Dostoievski ya no entienda nada de las preguntas que se le hacen (Dostoievski, 1953, 746). ¿Por qué? Una vez más, creemos que la respuesta más clara a esta pregunta se encuentra en las reflexiones sobre el pensamiento de Diferencia y repetición.

Para obtener una caracterización del viejo idiota a través de la tontería, previamente nos detuvimos en el fin, el riesgo y el modelo del pensamiento. Ahora es necesario detenerse en lo que Deleuze llama las “condiciones" del pensamiento y sus consecuencias, a saber, el sentido, los problemas o las preguntas, por un lado, y la verdad, las soluciones o las respuestas, por otro, dado que aquello que no entiende el protagonista de Dostoievski son justamente las preguntas que se le hacen. De acuerdo con la reconstrucción de la imagen dogmática del pensamiento que realiza Deleuze, la misión del pensador o del filósofo consiste en encontrar la mejor solución posible a un problema dado, la mejor respuesta posible a una pregunta dada. Sin embargo, algunos problemas, o bien parecen no tener solución, o bien sus soluciones parecen todas insatisfactorias. Por eso puede ser necesario hacer la crítica del problema mismo, trasladar la verdad y la falsedad al problema mismo, afirma Deleuze siguiendo a Bergson (Deleuze, 1968, 207). Cuando un problema no conduce a soluciones satisfactorias o no tiene solución, es el 
problema mismo lo que es falso, y no sólo su solución. Tal es el caso, por ejemplo, de las falsas alternativas. Si se nos propone elegir entre la inseguridad o la represión, por ejemplo, tal vez no queramos elegir ninguna de las dos opciones e intentemos imaginar una tercera. Pero eso implica reformular el problema. Técnicamente, no se puede decir que el problema inicial sea "resuelto", porque no se elige y demuestra una de las soluciones que él plantea. Pero tampoco se lo deja sin solución. Desaparece por el mero hecho de formularse correctamente, de transformarse en un problema verdadero. En la nueva imagen del pensamiento, la tarea del pensador, del filósofo, no consiste en resolver problemas dados, sino en crear problemas, reinventar los problemas, reformular los problemas, contestando, cuestionando los problemas dados (Deleuze, 1968, 207-208). Por eso es de lo más significativo que el príncipe Myshkin no entienda nada de las preguntas que se le hacen. Es el indicio de un cuestionamiento de los problemas y la justificación de por qué el nuevo idiota se construye a imagen y semejanza del personaje de Dostoievski. El nuevo idiota, el idiota ruso no quiere resolver los problemas, sino inventarlos, crearlos, y con ellos, sus soluciones. Pero para hacerlo, de alguna manera, debe desentenderse de los problemas dados o, como le ocurre al príncipe, de las preguntas que se le hacen. En esto consiste la nueva forma de la idiotez. Y del mismo modo que un determinado personaje en Diferencia y repetición, el tonto, correspondía al viejo idiota, existe ahora un personaje de Diferencia y repetición que corresponde a este nuevo idiota. Es el loco, el esquizofrénico, dado que "la esquizofrenia no es sólo un hecho humano", sino "una posibilidad del pensamiento" (Deleuze, 1968, 192). De hecho, "caracteriza la más alta potencia del pensamiento" (Deleuze, 1968, 82), es decir, la creación, y por eso el idiota ruso, el loco, se vuelve, ahora sí, el personaje filosófico por excelencia.

El esquizofrénico, el loco, el idiota ruso, no aspira al conocimiento ni al saber. No busca verdades ni evidencias. Quiere aprender o crear. Por eso no es un personaje conceptual entre otros ni el personaje privilegiado de ciertas filosofías del pasado. El idiota ruso es el personaje filosófico por excelencia en la medida que él mismo, reformulando problemas, crea conceptos. Es el personaje que Deleuze y Guattari utilizan para dar cuenta, no de lo que los filósofos de la tradición dijeron, sino de lo que hicieron, es decir, de sus creaciones, y por eso pueden preguntar retóricamente, al término de la caracterización del idiota: “¿Descartes en Rusia vuelto loco?" (Deleuze y Guattari, 1991, 61). Finalmente, el idiota ruso o esquizofrénico es el personaje que Deleuze y Guattari utilizan para producir sus propios conceptos. En definitiva, es él quien dice "yo" en la filosofía de Deleuze y Guattari, aun si, o justamente porque, en el marco de su filosofía, "yo" es otro o muchos, como se dice en el prólogo al segundo tomo de Capitalismo y esquizofrenia (Deleuze y Guattari, 1980, 8). Ahora bien, ¿qué indica este personaje sobre la idiotez? ¿Qué concepción de la idiotez presupone? Sin duda, ahora la idiotez parece haber cambiado, no sólo de forma y contenido, sino de lugar y valor: ya no constituye el polo positivo de la imagen dogmática del pensamiento (la tontería), sino el positivo de la nueva (la creación). Ya no se opone ni al pensamiento como conocimiento, como lo hace el error, ni al pensamiento como creación, como lo hace la tontería. Identificada a la locura y a la creación, la idiotez constituye ahora la esencia del pensamiento mismo, al menos en su forma filosófica. Sin embargo, no podemos dejar de observar que, aun si la idiotez cambia de valor y lugar, los lugares y valores permanecen idénticos, estableciéndose así una continuidad entre dos concepciones que siempre definen a la idiotez en relación al pensamiento y su oposición, asimilando el pensamiento al bien y su negación, al mal. 


\section{Los idiotas que ríen de la creencia en este mundo}

El idiota aparece una vez más en la obra de Deleuze - aun si lo hace seis años antes de la publicación de que ¿Qué es la filosofía? Se trata de una aparición tan fugaz como extraña. No se asemeja en nada a las caracterizaciones previas de los idiotas y parece constituir más bien un uso casi distraído.

Necesitamos una ética o una fe, escribe Deleuze en La imagen-tiempo, lo que hace reír a los idiotas; no es una necesidad de creer en otra cosa, sino una necesidad de creer en este mundo de aquí; del cual los idiotas forman parte (Deleuze, 1985, 225).

Se trata en efecto de un pasaje extraño, porque usualmente en la filosofía de Deleuze la inmanencia es el objeto o el medio del pensamiento y la trascendencia, el objeto o el medio de la creencia. Aquí, sin embargo, este mundo (la inmanencia) se vuelve el objeto de la creencia, inaugurando lo que parece una nueva forma de religiosidad. Nueva, porque concierne a este mundo; de religiosidad, porque bien implica una fe, una creencia. Ahora bien, ¿qué relación guardan estos últimos idiotas con esta nueva fe? En ningún caso parecen ser sus profetas, dado que ríen de la creencia ${ }^{5}$. No ríen, sin embargo, de la creencia en otro mundo, sino, de máxima, de la creencia en general, y de mínima, de la creencia en este mundo. ¿Quiénes son entonces? ¿Debemos pensarlos a partir del viejo idiota, el tonto? ¿O debemos considerarlos a partir del nuevo, el ruso, el loco? ¿Podría ser que se hable de ellos en plural porque su figura incluye a ambos? Una distinción más avanzada entre el pensamiento y la creencia, junto con la precisión de lo que Deleuze entiende por "este mundo", mostraría probablemente que estos últimos idiotas no pueden asimilarse a las figuras anteriores. Pero tal distinción y precisión excede las posibilidades de este artículo. Tal vez, por el momento, sea suficiente un breve análisis de la risa de estos últimos idiotas para ofrecer un indicio de su especificidad.

Deleuze estudió fundamentalmente dos procedimientos de la comicidad: el humor, definido en la Presentación de Sacher-Masoch como una crítica de la ley a partir de lo mejor relativo; y la ironía, definida como una crítica de la ley a partir de un principio superior, Bien o Justicia (Deleuze, 1967, 71). Con ellos, Deleuze explica la risa de los discípulos de Sócrates en el momento de su muerte y, naturalmente, la comicidad de Sade y de SacherMasoch. Pero estos procedimientos no explican la risa de Giap o Nasser (Deleuze, 2002, 181), a quienes Deleuze atribuye una "risa loca" [fou rire] o "risa esquizofrénica" cuya

5 Esta es la razón por la cual, respecto de este punto, no podemos seguir la lectura de Philippe Mengue, que afirma que "cuando Deleuze llega, en La imagen-tiempo, a plantear la idea de que lo que hace falta es "creer en este mundo', recurre, sin decirlo explícitamente, de nuevo al idiota" (Mengue, 2013, 70). En su libro, Mengue no sólo privilegia lo que los diferentes tipos de idiotas tienen en común, ofreciendo un único tipo de idiota, sino que asimila esta figura general del idiota a Cristo. Así, el idiota de La imagen-tiempo se vuelve el profeta de la nueva fe, cuando de acuerdo con el pasaje citado, parece ser todo lo contrario. Tal vez este último idiota no ría específicamente de la creencia en este mundo, pero ríe de la creencia, que incluye la creencia en este mundo y, por lo tanto, en ningún caso podría ser un creyente, y menos el profeta, de esta nueva forma de religiosidad. Parece ser, muy al contrario, su detractor. 
definición debe ser construida, pero que siempre aparece asociada a una creación ${ }^{6}$. Si la risa del idiota tradicional parece una risa irónica, porque contesta cierta ley, la de la autoridad, la del saber escolástico, a partir de un principio superior que identifica con la razón, y si la risa específica del idiota ruso parece ser lógicamente la risa loca (aun si ironiza cuando dice que el destino del pensamiento no se juega en reconocer a Teeteto cuando efectivamente es Teeteto quien pasa), la risa de los últimos idiotas no puede identificarse con ninguna de las precedentes. En efecto, no parecen disponer de un principio superior ni defender un bien relativo para hacer la crítica de este mundo; y ningún pensamiento, ninguna creación parece asociada a ellos. Simplemente ríen. Ríen, ya sea de la creencia en general, ya sea, quizá, especialmente de la creencia en este mundo.

¿Pero por qué ríen? ¿Por qué la creencia en este mundo, si es de eso que ríen particularmente, habría de causarles risa? Que se nos permita avanzar una hipótesis, tal vez algo vaga y arbitraria, pero que podría precisarse en el futuro y justificarse a través de su utilidad. Tal vez los idiotas rían de la creencia en este mundo porque, aún si forman parte de él, conservan con él una cierta distancia, en el sentido más concreto e inmediato posible, a saber, tanto en términos espaciales como temporales. En efecto, si dirigimos nuestra atención sobre los personajes ya mencionados, podremos observar que, si bien no se hallan en otro mundo, se hallan lejos del aquí y ahora que definen a éste, de su presente y sus centros, por decirlo de algún modo. Comencemos, entonces, considerando el espacio que nuestros idiotas habitan. ¿Cómo se determina, en primer lugar, el espacio del De mente de Nicolás de Cusa? ¿Dónde acontece el diálogo? ¿Qué define al aquí de ese mundo, cuáles son sus centros? Para empezar, pensemos en el templo, que constituye el lugar de la fe y el saber. Desde cierto punto de vista, allí deberíamos encontrar al idiota, al verdadero pensador del diálogo, porque es allí donde "se encuentran muchos escritos sabios acerca de la mente" (Cusa, 2005, 39 [53]). También lo podríamos encontrar en el foro, el lugar de la palabra, de la oratoria, de la tradición de Cicerón. Sin embargo, el idiota no se encontrará allí y tampoco en la plaza pública, esta vez, a donde el idiota, en el primero de los diálogos, conducía al orador para hacerle comprender el paradójico camino hacia la verdadera sabiduría. ¿Dónde se encuentra entonces? En un pequeño ámbito subterráneo donde fabrica cucharas para vender en el mercado. El hecho de que se trate de un recinto subterráneo, de alguna manera, ya separa al idiota del mundo, de su mundo, del aquí de su mundo. Lo más importante, sin embargo, consiste en la razón por la que se encuentra allí y en la actividad que allí desempeña. En aquel recinto subterráneo, el idiota fabrica cucharas para vender en el mercado. ¿Por qué? Porque sólo en el mercado la mente puede ejercer sus actividades propias: pesar, medir, numerar. El lugar propio del idiota, entonces, no es el tempo ni el foro, los lugares de la fe y el saber, tampoco la plaza pública ni, estrictamente, el recinto subterráneo donde se lo encuentra de hecho. Su lugar de derecho, el lugar que lo define y, con él, a su idiotez, es el mercado, el lugar de la razón. Así, la idiotez queda definida en parte gracias a una localización y, esta localización, a partir de una distancia con los lugares del saber tradicional. El idiota cartesiano,

6 "Las grandes coincidencias son por ejemplo el estallido de risa de Nasser al nacionalizar Suez, (...) y ese otro estallido de risa, el de Giap entrevistado en la televisión. (...) Hay creadores en política, movimientos creadores, que se dan en ciertos momentos de la historia (Deleuze, 2002, 180-181). 
en segundo lugar, ni siquiera vive en la ciudad. Vive en una retirada casa de campo que, según Descartes, hay que imaginar como un lugar rodeado de "desiertos infértiles y de montañas inhabitables” (Descartes, 1953a, 1953). ¿Por qué un retiro tan radical? Porque sólo allí este idiota puede dudar incluso de las actividades más propias de la mente. Si el idiota cartesiano ya no está ni siquiera en el mercado, es porque necesita dudar incluso de lo que el idiota cusano considera como verdadero. Vive en el campo, en soledad, porque incluso de la aritmética debe poder dudar. Exhibe así, nuevamente - y tal vez con mayor fuerza, dado que se encuentra más lejos - en qué medida el idiota, si bien se encuentra en el mundo, se halla retirado de él, y en qué medida la idiotez se define en parte gracias a este retiro. Finalmente, la distancia o la lejanía que conciernen al príncipe Myshkin son todavía mayores. En efecto, el personaje de Dostoievski no vuelve a Rusia ni de la periferia ni del campo, sino del exterior, del extranjero, de una aldea Suiza, en particular, en la que pasó la mayor parte de su exilio. Era un extranjero allí, porque venía de Rusia, y es un extranjero ahora, en Rusia, porque vuelve de Suiza. Y si la distancia geográfica con su mundo es mayor que la que guardan los personajes de Cusa y Descartes con el suyo, es porque, en cierto sentido, su idiotez lo es. Recordemos, en efecto, que, en sus peores momentos, el príncipe ni calcula ni duda, sino que sombra en la más extrema locura. Extranjero entre los rusos, extraño entre los hombres, el personaje de Dostoievski parece presentar entonces una distancia con su mundo aun mayor que la de los personajes de Cusa y Descartes. Confirmaría así la existencia de una proporción entre el grado de idiotez y la distancia respecto de un lugar de referencia y, por lo tanto, mostraría cómo una cierta distancia o lejanía parece contribuir a la descripción de la idiotez.

Alejados, distanciados, desplazados en el espacio, los idiotas también parecen estarlo en el tiempo. En efecto, es posible observar cómo los personajes en cuestión guardan una distancia también con los tiempos que definen a sus mundos respectivos, con un cierto ahora que los organiza. Consideremos, nuevamente, para empezar, el diálogo de Cusa. ¿Cómo se determina su temporalidad? ¿Cuándo se desarrolla el diálogo? El De mente no se desarrolla en la eternidad, en un universo sin tiempo, en el universo de la lógica, pese a que esta temporalidad parezca definir algunas de sus operaciones. Tampoco se desarrolla según la mera sucesión de las ideas, ni en el tiempo cíclico de la naturaleza, marcado por ejemplo por sus estaciones. Se desarrolla durante un tiempo humano que no se reduce a la fecha o la época. Este tiempo, precisamente, corresponde al Jubileo, la máxima celebración religiosa que reúne a las distintas Iglesias. Ahora bien, se recordará que el idiota no asiste a la ceremonia, y que el "minucioso coloquio" del que participa es el diálogo que mantiene con el filósofo y el orador (Cusa, 2005, 43 [56]). Así, el idiota no se sustrae sólo a los lugares de la fe y el saber, sino también a sus tiempos, y la idiotez queda ahora caracterizada, no por una distancia geográfica, sino por un distanciamiento que concierne al tiempo de referencia del mundo en el que se inserta. ¿Qué sucede con Eudoxo en este sentido? ¿Acaso la distancia en relación a los tiempos de su mundo es mayor que la del idiota cusano, así como es mayor la distancia geográfica que caracteriza su ubicación? Consideremos el famoso movimiento inicial según el cual el meditador propone deshacerse de todas sus creencias para establecer un fundamento seguro para las ciencias. Ese movimiento se realiza de acuerdo con coordenadas temporales muy precisas. Para empezar, el meditador advierte que, desde sus primeros años, tomó lo falso por verdadero. En 
segundo lugar, no lo advierte en el presente de la meditación, sino que confiesa haberlo advertido hace ya algún tiempo. En tercer lugar, confiesa que, habiéndolo advertido, decidió esperar hasta tener una edad madura para iniciar la empresa, tan exigente era (Descartes, 1953b, 267). En síntesis, su meditación está marcada por dos recuerdos y una espera: el recuerdo de sus primeros años en el momento del descubrimiento, el recuerdo del descubrimiento en el momento del inicio de la meditación y la espera hasta tener una edad madura en el momento del descubrimiento. Así, el idiota cartesiano no se desentiende únicamente de una celebración, no se sustrae únicamente del tiempo social, sino que en dos ocasiones distintas abandona incluso el presente objetivo de su mundo, el presente exterior, el presente de la percepción. En cada una de esas ocasiones, los recuerdos y la espera lo llevan más allá, hacia el pasado y hacia el futuro, alejándolo en una y otra dirección del ahora de su mundo. El idiota cartesiano no se desentiende sólo, en el presente, de una fecha en el calendario religioso, como el idiota cusano, sino que por medio de un retorno a una edad anterior se desentiende del presente mismo. Por eso su distancia con el tiempo de su mundo parece mayor que la distancia que caracteriza al idiota cusano. Ahora bien, en el caso de Eudoxo, el retorno a un tiempo anterior constituye un signo de madurez y sabiduría. En el caso del príncipe Myshkin, al contrario, constituye un signo de inmadurez, dado que se siente "como un niño en un mundo de adultos" (Dostoievski, $1953,91)$. No es una manera de decir: se recordará que, en el caso del príncipe, la idiotez no constituye un proyecto filosófico, sino una patología acompañada por crisis de epilepsia. Por eso tal vez quepa esperar que la distancia temporal del príncipe con su mundo sea todavía mayor a la de Eudoxo con el suyo. De hecho, Alfred Binet y Théodore Simon intentaron cuantificar esta distancia o desfasaje creando la escala para medir la inteligencia y, con ella, la categoría de edad mental. A partir de entonces, se le intentó asignar a la inteligencia de los idiotas e imbéciles una edad tan precisa como la de sus cuerpos y la categoría psiquiátrica de "retraso" - todavía vigente en la CIE-10 - comenzó a exhibir toda su positividad. No es necesario, sin embargo, intentar medir la inteligencia o el retraso del príncipe para constatar que la distancia con el tiempo de su mundo es mayor que la de los idiotas precedentes. El príncipe Myshkin no se desentiende, en el presente, de una fecha del calendario religioso, y tampoco sólo se sustrae del presente por medio de recuerdos o esperas. El príncipe Myshkin, al menos durante las crisis de epilepsia o en el desmoronamiento final, abandona incluso el pasado y el futuro de este mundo para adoptar una temporalidad de la que poco sabemos, pero que podemos imaginar que presenta reglas muy distintas a las del tiempo objetivo o convencional. Para resumir, diremos que la distancia que los idiotas en cuestión mantienen con el tiempo de su mundo también parece guardar una relación con su grado de idiotez y que, por lo tanto, una cierta distancia o desfasaje temporal parece caracterizar a la idiotez tanto como la lejanía en el espacio. Los idiotas parecen alejarse tanto de los espacios y lugares que determinan sus mundos respectivos como de las fechas y de las dimensiones de su tiempo. Podrán no estar en otro mundo, pero puede verse que tampoco se hallan en el centro de éste.

Las condiciones espacio-temporales de la creación filosófica, en el marco de la filosofía deleuziana, parecen confirmar estas observaciones. En efecto, siguiendo a Nietzsche, Deleuze y Guattari insisten en el hecho de que el filósofo debe ser "intempestivo" (Deleuze y Guattari, 1991, 107). Se refieren a que el filósofo no debe ni sustraerse al tiempo para pensar 
en la eternidad, ni dejarse llevar por el tiempo entendido como moda y época. Crítico de su era, debe, sin salirse del tiempo, contestar el presente y pensar en el porvenir. Y en la medida que, como hemos visto, el idiota ruso corresponde a la figura deleuziana del filósofo, los caracteres de uno pueden ser inmediatamente transferidos al otro. Paralelamente, la misión del filósofo no consiste en legitimar territorios sino, nuevamente, en sustraerse a los códigos, normas y convenciones que delimitan el espacio, en "desterritorializarse" según los términos de Deleuze y Guattari, para eventualmente construir nuevos espacios (Deleuze y Guattari, 1991, 67). De hecho, el análisis que Philippe Mengue realiza del personaje deleuziano del idiota insiste particularmente sobre este punto. Su función, nos dice Mengue, consiste en generar una zona de indeterminación y, más precisamente, un "espacio de deslizamiento" [glissement]" en el que un hecho absolutamente novedoso pueda producirse (Mengue 2013, 64). Intempestividad y desterritorialización constituyen así las modalidades particulares bajo las cuales el idiota deleuziano, sin dejar de pertenecer a este mundo, entabla una relación crítica con sus espacios y sus tiempos.

Los distintos idiotas no tienen la misma relación con los espacios y los tiempos de sus mundos respectivos y estos espacios y tiempos ni siquiera se caracterizan de la misma manera. A veces constituyen centros de saber; otros, centros de poder. A veces constituyen la fecha de una celebración religiosa; a veces, las dimensiones gracias a las cuales nos orientamos en el tiempo. Pero de distintas maneras y en relación con distintos tiempos y espacios que funcionan como puntos de referencia o como centros, los idiotas parecen distanciarse. Tal vez por eso, entonces, los últimos idiotas que pusimos de relieve en la obra de Deleuze rían de la creencia en este mundo. En el campo, bajo tierra, extranjeros, inmaduros, retrasados, intempestivos, desterritoralizados, los idiotas miran el aquí y ahora de este mundo desde lejos, y tal vez por eso puedan dudar de él, reír, enloquecer o inventar.

\section{Conclusión}

En la vida ordinaria y el lenguaje corriente, muchas veces la idiotez remite a una falta de inteligencia, a un defecto del pensamiento, a una falla en el razonar o un defecto en el desempeño de tareas que involucran competencias intelectuales. Se trata de una concepción que alcanzó gran precisión en la psiquiatría clásica y que no se halla totalmente ausente de la filosofía contemporánea. A juicio de Deleuze y Guattari, el idiota constituye el personaje filosófico por excelencia. ¿En qué medida este personaje ofrece una concepción alternativa de la idiotez? Hemos visto que, en realidad, existen al menos tres tipos de idiotas en la filosofía de Deleuze, desarrollada solo o en colaboración con Guattari. Uno de ellos no parece introducir grandes cambios. Es el que puede identificarse con el tonto. Es cierto, este idiota ya presupone una concepción del pensamiento en la que el pensar no se reduce a conocer, sino que equivale a crear. Pero no es el tonto, el idiota de Descartes quien ejerce este tipo de pensamiento, quien piensa verdaderamente. Por eso, en su caso, la idiotez o tontería sigue constituyendo la negación del pensamiento. En cierto sentido, el segundo tipo de idiota parece invertir por completo la concepción de la idiotez, porque el idiota ruso o el loco es justamente el responsable de la creación conceptual. Así, la idiotez, en vez de oponerse al verdadero pensamiento, parecería identificarse con él. No obstante, quien dice invertir no dice revertir: los presupuestos de esta concepción 
de la idiotez, a saber, la limitación de la idiotez a la esfera del pensamiento, la asimilación del pensamiento al bien y de su oposición al mal, siguen siendo los mismos. Existe, sin embargo, un tercer tipo de idiota en la filosofía de Deleuze aunque, es cierto, mucho menos desarrollado. Se trata del idiota que ríe de la creencia y, tal vez, particularmente, de la creencia en este mundo. No sabemos demasiado sobre él, y por eso aprovechamos esa vacancia para construir la hipótesis según la cual su risa podría expresar una cierta distancia con este mundo, tanto en un sentido espacial como en un sentido temporal. El análisis de los personajes a los que recurren Deleuze y Guattari para construir su propio idiota, a saber, el idiota cusano, Eudoxo y el príncipe Myshkin, así como el análisis de la figura del filósofo en la obra de Deleuze, parecen confirmar la hipótesis dado que, de un modo u otro, siempre parecen alejarse, retirase, sustraerse de ciertos espacios y tiempos determinados que constituyen el mundo al que pertenecen.

Sin duda, se trata de una hipótesis algo vaga y arbitraria. ¿Qué figura no implica ciertos movimientos en el tiempo y el espacio, distancias más o menos variables con los espacios y tiempos que determinan su mundo? Para alcanzar mayor precisión, habrá que analizar las coordenadas y los movimientos particulares que definen a la figura del idiota, como personaje literario, como personaje conceptual y como antiguo cuadro clínico, y no sólo interrogar si existen diferencias con las figuras vecinas, como puedan ser la imbecilidad o la estupidez, sino determinar las diferencias con, por ejemplo, otros cuadros, como la manía o la melancolía. En cuanto a la arbitrariedad, tal vez por el momento pueda compensarse con su utilidad. En efecto, una tal concepción de la idiotez se revelaría, en relación con la anterior, más amplia desde un punto de vista ontológico, positiva desde un punto de vista lógico y relativa desde un punto de vista ético. Más amplia, porque no concerniría sólo al pensamiento, sino a la existencia en general. La idiotez no sería una categoría, es decir, una forma del pensamiento, sino un existenciario, a saber, un modo de la existencia ${ }^{7}$. Positiva, porque no implicaría una relación de oposición o negación, un más y un menos, una presencia y una ausencia, una deficiencia y una excedencia, sino una diferencia en un sistema de infinitas modalidades. La idiotez no se opondría al pensamiento como la oscuridad a la luz, sino que tendría un color propio en la gama infinita que corresponde a la vida. Relativa, finalmente, porque el valor de la idiotez dependería de los intereses prácticos o teóricos en juego, pero no estaría adosado a su naturaleza. Por supuesto, no se trata de subestimar el inmenso dolor que un antiguo cuadro clínico pueda haber producido en los pacientes y su entorno, pero tampoco se trata de aceptar sin cuestionar la aparente carga peyorativa de un fenómeno. Si la idiotez se definiese, por ejemplo, a partir de cierta lentitud, de cierto retraso temporal, aunque ya no en términos intelectuales, sino existenciales, ¿no podría revelar insospechados valores en una época marcada por la aceleración? Forma de existencia o modo de vida, la idiotez no dejaría de presentar vicios o virtudes. Pero estos se sancionarían pragmáticamente y ya no podrían hacerse pasar por características esenciales, tanto en las condenas como en los elogios de la idiotez.

7 Tal es la sugerencia de Jacques Derrida en relación a la tontería [bêtise] (Derrida, 2008, 209), y también se recordará que así concebía Ludwig Binswanger las enfermedades mentales en general, como bien lo señala Caroline Gros-Azorin en el prefacio a la edición francesa de El problema del espacio en psicopatología (GrosAzorin, 1998, 20). Actualmente, esto constituye uno de los presupuestos de los Disability Studies. 


\section{Referencias}

Asociación Americana de Psiquiatría (2014), Manual diagnóstico y estadístico de los trastornos mentales, $5^{\text {a }}$ edición, trad. a cargo del CIBERSAM (Centro de Investigación Biomédica en Red de Salud Mental), Asociación Americana de Psiquiatría, Arlington.

Deleuze, Gilles (1967), Présentation de Sacher-Masoch, Les Éditions de Minuit, París.

Deleuze, Gilles (1968), Différence et répétition, Presses Universitaires de France, París.

Deleuze, Gilles (1985), Cinéma 2. L’image-temps, Les Éditions de Minuit, París.

Deleuze, Gilles (2002 [1967]), “L'éclat de rire de Nietzsche”, en L'île déserte, Les Éditions de Minuit, pp. 178-182.

Deleuze, Gilles, y Félix GUATTARI (1980), Mille plateaux. Capitalisme et schizophrénie 2, Les Éditions de Minuit, París.

Deleuze, Gilles, y Félix GUATTARI (1991), Qu'est-ce que la philosophie?, Les Éditions de Minuit, París.

Derrida, Jacques (2008), La bête et le souverain, Galilée, París.

Descartes, René (1953a), La recherche de la vérité par la lumière naturelle, in Cuvres et lettres, Gallimard, Bibliothèque de la Pléiade, París.

Descartes, René (1953b [1641]), Méditations métaphysiques. Euvres et lettres, in Euvres et lettres, Gallimard, Bibliothèque de la Pléiade, París.

Dostoïevski, Fiodor (1953 [1869]), L'idiot, trad. de A. Mousset, B. de Schloezer y S. Luneau, Gallimard, Bibliothèque de la Pléiade, París.

Gros-Azorin, Caroline (1998), "Préface", in Ludwig Binswanger, Le problème de l'espace en psychopathologie, Presses Universitaires du Mirail, Toulouse.

Heidegger, Martin (1977), "Nietzsches Wort 'Gott ist tot'”, in Gesamtausgabe I. Abteilung: Veröffentlichte Schriften 1914-1970, Band 5: Holzwege, Vittorio Klostermann, Frankfurt am Main, pp. 209-269.

Kraepelin, Emil (1915), Ein Lehrbuch für Studierende und Ärzte, $8^{\mathrm{a}}$ edición, tomo 4, parte 3, Johann Ambrosius Barth, Leipzig.

Mengue, Philippe (2013), Faire l'idiot, Germina, París.

Nicolás De Cusa (2005), Idiota. De mente, ed. bilingüe, trad. de Jorge M. Machetta, Biblos, Buenos Aires.

Nicolai De Cusa (1983), Idiota. De mente, in Opera Omnia V, ed. L. Baur y R. Steiger, Felix Meiner: Hamburg, pp. 48-160.

Organización Mundial de la Salud (1995), Clasificación Estadística Internacional de Enfermedades y Problemas Relacionados con la Salud, $10^{\mathrm{a}}$ revisión, trad. a cargo del Centro Venezolano de Clasificación de Enfermedades, Organización Panamericana de la Salud, Washington.

Pinel, Philippe (1801), Traité médico-philosophique sur l'aliénation mentale, Caille et Ravier, París.

Roger, Alain (2007), Bréviaire de la bêtise, Gallimard, París.

Rosset, Cément (2004 [1977]), Le Réel. Traité de l'idiotie. Les Éditions de Minuit, París. 